\title{
Continuing educational forum in psychogeriatrics for professional carers in the community
}

\author{
E. Cybulska
}

It has been common knowledge that professional carers in the community, institutions, and perhaps also in hospitals lack appropriate training in issues related to mental health problems in the elderly. Many crises in the community appear to be precipitated not so much by the gravity of the problems the elderly pose, but by panic or the fear of the unknown among the carers. Arle et al (1985) postulate that the joint teaching of different professions can be a fruitful training for subsequent team work, while Beynon \& Croker (1983) reported that shared tutorials in geriatrics at the Middlesex Hospital in London were very successful. The negative features of institutionalised care can be counteracted through training and management (Willin et al, 1985).

A training programme was set up by a Senior Registrar in Old Age Psychiatry and the Consultant Psychogeriatrician at Thameslink NHS Trust in Dartford, Kent, in the Autumn of 1992 and ran for 18 months (allowing for Summer and Christmas recesses). The seminars took place once a month, on every third Wednesday, between 1.00 and $2.00 \mathrm{pm}$ in the hospital training suite, with buffet lunch provided by courtesy of the Trust management. Quite apart from the training per se, these meetings aimed to provide an opportunity for exchanging views between various groups of professional carers, bring closer the private and public sector, abolish the 'them' and 'us' barriers, and last but not least to provide an opportunity for those who are the front-liners, such as nursing staff, to share their rich experience and raise the profile of their work.

The audience consisted of care assistants of state run and private residential and nursing homes, home care managers, home carers, community psychiatric nurses (CPNs), nurses, junior doctors, members of various voluntary organisations such as Age Concern, Crossroads, Alzheimer's Disease Society. Occastonally, relatives and carers were also invited. In the first year the speakers were recruited among the health workers from the Trust but the following year some outside lecturers were invited and members of the audience were also encouraged to come to the forum. The list of the topics presented and discussed is presented in Table 1 . It is worth noting that less than half of the talks were given by the doctors, one was given by the Director and the rest were given by nurses, some of them in managerial disguise. All the speakers with the exception of the Mental

Table 1. List of topics presented and discussed

Nursing patients with Althelmer's

(Ward Manageress Elderly Mentally Infirm - EMD

Group psychotherapy for the elderly (CPN)

Depression in the elderly

(Consultant Psychogerlatrician)

Managing aggresstve patients

(Ward Manager - EMI Assessment Unit)

Making senvices work

(EMI team leader)

Crisis intervention

(Senlor Registrar in Psychogeriatilics)

Caring for the confused elderly

(Relatives' forum (3 speakers from the audience introduced by Consultant Psychlatist))

Common medical problems in the elderly (Consultant Geriaticician)

The importance of leadership (Mental Health Director)

The role of CPNs (CPN Manager)

Paranold states in the elderly (Consultant Psychogeriatrician)

Coping with loss and bereovement (invited Psychogeriatilician)

Drugs \& the elderly, a friend or a foe? (Registrar) 


\title{
EDUCATION
}

Health Director were directly involved in the care of the patients. The attendance varied from 10 (the very first talk) to a maximum of 62, with the median of 30 . There were lively discussions during the meetings and also afterwards.

The feedback from the participating audience was very encouraging with comments such as "so many things I did not know", "now I understand why I was so intolerant" or simply "I did not know that this is the way my client thought". "it is good to know that you are there". "it is reassuring to know that there are many things you do not know too"!

After 18 months we decided to temporarily suspend the forum in order to take stock and improve our own knowledge before embarking on the next training programme.

\section{References}

ARE, T., JONES, R. SMmt, C. H. (1985) The educational potential of poychogeriatric services, Ch. 13. In Recent Advances in Psychogerlatrics (ed. T. Arte). pp 197-207. Edinburgh, London, New York: Churchill Livingstone.

BEYNON. G. P. CROKER, J. (1983) Multidisciplinary education in gertatric medicine. Age and Agting. 12 (Suppl.). 26-29.

WuKIN, D., Hughes, B. \& JouY, J. D. (1985) Quality of care in institutions, Ch. 8. In Recent Advances in Psychogerlatrics (ed. T. Arie), pp 103-118. Edinburgh. London. New York: Churchill Ltvingstone.

E. Cybulska, Consultant Psychiatrist, Thameslink Healthcare Services NHS Trust, Cotton Lane, Dartford, Kent DA2 6AU

\section{Clinical pharmacists: the benefits for psychiatric trainees}

\author{
Graeme Yorston and Evelyn McPhail
}

Psychiatric trainees' knowledge and understanding of the therapeutic principles underlying the appropriate use of psychotropic medication comes from many sources. They receive a grounding in neuropharmacology as a medical student and this is updated and expanded by attendance at a university lecture course in preparation for the MRCPsych examinations. Practical advice is handed down by supervising consultants and is augmented by reference to standard textbooks and research literature. Pharmaceutical representatives occasionally provide useful information though this may be blased, concentrating on specific drugs in isolation and without comparisons to competitors. Because of the variety and uneveness of these sources there is a risk, especially in the earlier years of training that knowledge is patchy, impractical or unsoundly based on dogmatic or out of date advice. There have been calls for training in psychopharmacology to be improved and suggestions as to how this may be achieved (Ferrier \& Cooper, 1994). This paper describes the clinical pharmacy services in Flfe and their value in improving the knowledge and practice of therapeutics amongst psychiatric trainees.

Clinical pharmacists have a broad understanding of pharmacological and therapeutic principles. Training begins with a basic degree in pharmacy which provides a relatively limited knowledge of psychopharmacology, but over the past ten years there has been an increasing trend towards specialisation and further study in the clinical area of drug use leading to a diploma or masters degree in clinical pharmacy. Pharmacology and therapeutics are two of the main areas studied such 